\title{
The $f t s H$ Gene of Bacillus subtilis Is Transiently Induced after Osmotic and Temperature Upshift
}

\author{
ELKE DEUERLING, BETTINA PAESLACK, AND WOLFGANG SCHUMANN* \\ Institute of Genetics, University of Bayreuth, D-95440 Bayreuth, Germany
}

Received 8 November 1994/Accepted 27 April 1995

\begin{abstract}
The ftsH gene of Bacillus subtilis has been identified as a salt-sensitive insertion mutation in strain UG1. Here, we show that UG1 has an insertion near the 3 end of $f t s H$. The salt sensitivity of this mutant was caused by reduction of $f t s H$ mRNA levels by the synthesis of an artificial antisense RNA originating at a promoter located within the insertion and reading backwards into the $f$ ts $H$ gene. The salt-sensitive phenotype could be overcome by deleting the promoter from which the antisense RNA was transcribed. A physiological analysis of the isogenic wild-type strain in minimal medium revealed unimpaired growth at up to $1 \mathrm{M} \mathrm{NaCl,} \mathrm{and} \mathrm{growth}$ above 1.2 M NaCl was observed only after addition of the osmoprotectant proline or glycine betaine. In contrast, growth of strain UG1 was reduced at a salt concentration above $0.2 \mathrm{M}$, which could be rescued by the two compatible solutes already mentioned and also by trehalose. Primer extension revealed one potential transcription start site downstream of a putative vegetative promoter, which was activated after osmotic or temperature upshift. Northern (RNA blot) experiments led to the detection of a 2.1-kb transcript, suggesting that $f t s H$ is monocistronic. A transcriptional fusion between $\mathrm{fts} H$ and the gus reporter gene exhibited a twofold increase in $\beta$-glucuronidase activity after osmotic upshift. To further confirm the need for an enhanced level of FtsH protein after osmotic upshift, the promoter was replaced by the sucrose-inducible promoter $\mathbf{P}_{\text {sacB }}$. Whereas this mutant strain could grow in the absence of inducer in LB medium, it stopped growth immediately after addition of $1.1 \mathrm{M} \mathrm{NaCl}$. We conclude that an increased amount of FtsH protein is essential for B. subtilis to cope with an increase in osmolarity or temperature.
\end{abstract}

Bacteria have evolved sophisticated mechanisms that enable them to survive a variety of environmental stresses, including oxidative stress, extreme $\mathrm{pH}$, anaerobiosis, heat shock, osmotic shock, and starvation. They respond to these various stimuli by changing the expression of groups of genes termed stress genes, which encode specific sets of proteins that are characteristic of each stress (11). These proteins are thought to be important for adaptation to the new environment as well as for protection against future potentially lethal exposures to that stress. Understanding how these genes are regulated is fundamental to a comprehensive knowledge of cellular stress adaptation.

Exposure of bacteria to high osmolarity leads to dehydration, collapse of ion gradients over the cytoplasmic membrane, and decrease in cell viability. Therefore, the first response of bacteria to osmotic stress consists of changes in the activities of enzymes and of transport systems so that the turgor pressure is restored and the cytoplasmic environment is optimized. Somewhat later, changes in gene expression provide additional flexibility in adapting cells to upshock (for reviews, see references 7,8 , and 13). The regulation of gene expression in response to changing levels of osmolarity requires a sensor function to monitor increased levels of the osmotically active substance and an effector function to mediate a transcriptional and/or translational response. The molecular nature of both functions in eubacteria has still to be disclosed.

There are only a few publications dealing with osmotic upshock and the induction of stress proteins in Bacillus subtilis. After hypersaline treatment, the turgor pressure decreased, and subsequent recovery was $\mathrm{K}^{+}$dependent (43). Thereafter,

\footnotetext{
* Corresponding author. Mailing address: Institute of Genetics, University of Bayreuth, P.O. Box 1012 51, D-95440 Bayreuth, Germany. Phone: (49) 921 552708. Fax: (49) 921 552535. Electronic mail address: Wolfgang.Schumann@Uni-Bayreuth.De.
}

B. subtilis has been shown to accumulate proline, and proline synthesis appeared to be dependent on the prior accumulation of $\mathrm{K}^{+}(25)$. In cells upshocked in medium enriched in glycine betaine, the endogenous synthesis of proline was repressed and glycine betaine served as the sole organic osmoticum (44). Boch and coworkers reported that B. subtilis can synthesize glycine betaine from exogenously provided choline (5). In addition, salt stress turned out to be very effective in the induction of general as well as specific stress proteins $(13,40$, 41).

Recently, we have reported the isolation of a salt-sensitive insertion mutant in which the insertion turned out to affect an open reading frame (ORF) exhibiting significant homology to the fts $H$ genes of Escherichia coli (38) and Lactococcus lactis (26). The objective of the present study was to carry out an extensive physiological and transcriptional analysis of the fts $H$ locus in both the wild type and its isogenic insertion mutant and to find out why the mutant could not grow under high-salt conditions. During our analysis, we also found that $f t s H$ is transiently induced by heat. A possible role for the FtsH protein during stress is discussed.

\section{MATERIALS AND METHODS}

Bacterial strains, plasmids, and growth conditions. The bacterial strains and plasmids used are given in Table 1 . Bacteria were routinely grown aerobically at $37^{\circ} \mathrm{C}$ in Luria broth (LB). Spizizen minimal medium (SMM) has been described (35). Ampicillin and chloramphenicol were added at a concentration of 50 and 5 $\mu \mathrm{g} \mathrm{ml}{ }^{-1}$, respectively.

DNA manipulations and analysis. Standard methods were used for DNA isolation, restriction endonuclease analyses, and ligation (31). Restriction enzymes, T4 DNA ligase, and alkaline phosphatase were purchased from New England Biolabs, Stratagene, and Boehringer Mannheim and used as recommended by the suppliers. Digoxygenin (DIG)-[11]-ddUTP and the DIG detection kit were purchased from Boehringer Mannheim. Nucleotide sequences were determined by the dideoxy nucleotide chain termination method (32).

Deletion of $P_{\mathrm{Tc}}$ and determination of the insertion site of the pJH101 plasmid 
TABLE 1. Bacterial strains and plasmids

\begin{tabular}{|c|c|c|}
\hline Strain or plasmid & Characteristics & Source or reference \\
\hline E. coli $\mathrm{DH} 5 \alpha$ & endA1 gyrA96 hsdR17 $\phi 80 l a c Z \Delta \mathrm{M} 15$ supE44 deoR thi-1 $\Delta(\operatorname{lacZYA}-\arg F) U 169$ relA1 & 12 \\
\hline \multicolumn{3}{|c|}{ 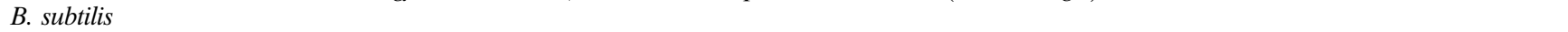 } \\
\hline 1012 & leuA8 metB5 $\mathrm{r}_{\mathrm{M}}^{-} \mathrm{m}_{\mathrm{M}}^{+}$ & 30 \\
\hline UG1 & 1012 with insertion of pJH101 at ftsH & 10 \\
\hline ED1 & 1012 with insertion of pUGE1 at $f t s H$ & This work \\
\hline ED2 & 1012 with a promoterless gus at the $a m y E$ locus & This work \\
\hline ED3 & 1012 with a transcriptional fts $H$-gus fusion at the $a m y E$ locus & This work \\
\hline ED10 & 1012 in which the promoter region of $f t s H$ had been replaced by a cat $-\mathrm{P}_{\mathrm{sacB}}$ cassette & This work \\
\hline \multicolumn{3}{|c|}{ e } \\
\hline pACYC177 & $\mathrm{Ap}^{\mathrm{r}} \mathrm{Km}^{\mathrm{r}}$ & 6 \\
\hline pUC18 & $\mathrm{Ap}^{\mathrm{r}}$ & 46 \\
\hline pBM4 & $\mathrm{Cm}^{\mathrm{r}}$ & 21 \\
\hline pMKL83 & $\mathrm{Ap}^{\mathrm{r}} \mathrm{Km}^{\mathrm{r}}$ & 18 \\
\hline pBluescriptKS ${ }^{+}$ & $\mathrm{Ap}^{\mathrm{r}}$ & Stratagene \\
\hline pUG1E & Chromosomal DNA of UG1 cut with EcoRI and self-ligated & This work \\
\hline pED02 & pMKL83 carrying a transcriptional fts $H$-gus fusion & This work \\
\hline pED05 & 3.6-kb HindIII chromosomal DNA fragment cloned into pACYC177 & This work \\
\hline pED1113 & $\begin{array}{l}\text { pUC18 with a cat marker and } \mathrm{P}_{\text {sacB }} \text { sandwiched between up- and downstream } \\
\text { sequences of } \mathrm{P}_{\mathrm{A}} \text { of ftsH }\end{array}$ & This work \\
\hline $\mathrm{pED} \Delta \mathrm{F}$ & Internal SstI-HindIII fragment of $f t s H$ cloned into pBluescriptKS ${ }^{+}$ & This work \\
\hline
\end{tabular}

within the bacterial chromosome of strain UG1. Strain UG1 contains the integration vector pJH101 inserted near the $3^{\prime}$ end of the fts $H$ gene. pJH101 is a derivative of pBR322, which contains a cat gene for selection in B. subtilis (9). To delete $\mathrm{P}_{\mathrm{Tc}}$ from UG1, the chromosomal DNA of UG1 was digested with EcoRI, the resulting fragments were self-ligated and transformed into E. coli $\mathrm{DH} 5 \alpha$, and transformants were selected on LB plates containing ampicillin. The recombinant plasmid isolated from one of these transformants was designated pUG1E and lacked the $\mathrm{P}_{\mathrm{Tc}}$ promoter (Fig. 1A). This plasmid was used to transform $B$. subtilis 1012, and integrants were selected on LB plates containing chloramphenicol. One such strain was named ED1, and the correct insertion of pUG1E within the $f t s H$ gene was confirmed by Southern blotting (data not shown). The insertion site of pJH101 within fts $H$ was determined by DNA sequencing with pUG1E.

Construction of a transcriptional fusion between $\mathrm{ftsH}$ and gus. To monitor expression of the $f t s H$ gene, a region upstream of the $f t s H$ structural gene was transcriptionally fused to the gus reporter gene and integrated at the $a m y E$ locus of the B. subtilis chromosome. To accomplish this goal, a 299-bp fragment

A

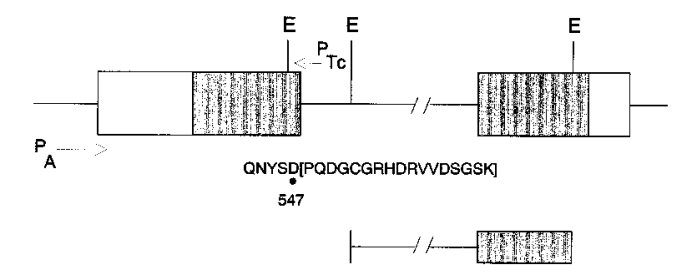

UG1

PUG1E

B

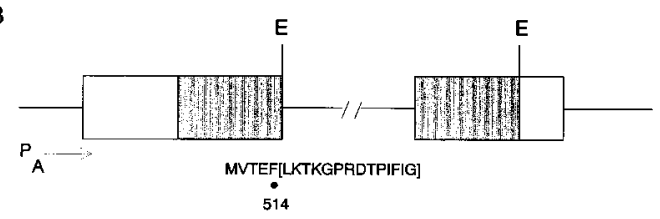

ED1

FIG. 1. Schematic representation of two fts $H$ insertion mutants. (A) Strain UG1 contains an insertion of the integration vector pJH101 (10). In pUG1E, the DNA sequences between the EcoRI and BamHI sites of pJH101 have been deleted, removing $\mathrm{P}_{\mathrm{Tc}}$. (B) Strain ED1 was obtained by integration of pUG1E. The DNA sequences of $f t s H$ which have been duplicated because of the insertion of the recombinant plasmids are drawn as hatched boxes. Below the fts $H$ gene, the five C-terminal amino acid residues of the truncated $\mathrm{FtsH}$ protein are given, followed by the fused foreign amino acid residues (in brackets) encoded by the plasmid; the last amino acid residue of the FtsH protein is indicated by a dot. The complete FtsH protein consists of 637 amino acid residues. $\mathrm{P}_{\mathrm{A}}$, vegetative promoter; $\mathrm{P}_{\mathrm{Tc}}$, tetracycline resistance promoter; E, EcoRI. corresponding to nucleotides 29 to 327 in Fig. 2B was generated through PCR amplification. A HindIII and a BamHI site were introduced at the $5^{\prime}$ end and the $3^{\prime}$ end, respectively. The HindIII and Bam HI double-digested fragment was then inserted into HindIII-BamHI-digested pMKL83 upstream of the gus gene. This vector carries a cassette consisting of a promoterless gus gene and a cat marker sandwiched between the two halves of the $a m y E$ locus, allowing integration of the whole transcriptional fusion at the chromosomal amyE locus by a double crossover event (18), resulting in strain ED3. Integration of the ftsH::gus operon fusion at amyE was verified by PCR with oligonucleotides from the two inside ends of the split amyE locus. Chromosomal DNA from an integrant with the promoterless gus gene served as a control (strain ED2). The activity of the gus gene (which encodes $\beta$-glucuronidase) was measured as described before with $p$-nitrophenyl- $\beta$-D-glucuronide as the substrate (17).

Construction of pED1113 and $\mathbf{P}_{\text {sacB }}-f$ ts $H$. Plasmid pED1113 was designed to replace the chromosomal fts $H$ with a modified $f t s H$ gene. The expression of this modified $f t s H$ gene was controlled by the inducible promoter from $s a c B$, a structural gene for levansucrase. To replace the vegetative promoter $\mathrm{P}_{\mathrm{A}}$ by the controlable $\mathrm{P}_{\mathrm{sacB}}$, DNA fragments of about 500 bp each up- and downstream of the vegetative promoter were generated by PCR. Both amplicons were used to flank a cassette consisting of a cat gene followed by $\mathrm{P}_{\mathrm{sacB}}$. Figure $2 \mathrm{~A}$ depicts the genomic organization of the $f t s H$ gene. To amplify the upstream region, oligonucleotides ON1 (5'-GGCCATGCATGCGTATCAAGATACATTTTCC GTTG GC-3'; SphI recognition site underlined) and ON2 (5'-GGCCATCTG CAGGGCTGCCGATCAGCTTTCATAAAC-3'; PstI) were used, resulting in a 487-bp amplicon. To generate the downstream region of $\mathrm{P}_{\mathrm{A}}$, oligonucleotides ON3 (5'-GGCCATGGTACCGTGCTTACTGTGGGAGGAGGTAAG-3'; KpnI) and ON4 (5'-GTTTTACCGGTACCCGGAGG-3') were used as primers, resulting in a 661-bp amplicon. The approximate locations of ON1 and ON4 are shown in Fig. 2A; the exact locations of ON2 and ON3 are shown in Fig. 2B. The cassette was recovered as a 1.8-kb PstI-KpnI fragment from pBM4 (21) and inserted into pUC18. The SphI-PstI double-digested fragment was inserted upstream and the KpnI-SstI double-digested fragment was inserted downstream of the cassette (there is an SstI recognition site immediately upstream of ON4). This plasmid was used to transform B. subtilis 1012. Chloramphenicol-resistant colonies were selected and verified for the replacement of $\mathrm{P}_{\mathrm{A}}$ by $\mathrm{P}_{\mathrm{sacB}}$ by $\mathrm{PCR}$ with oligonucleotides ON1 and ON4. The resulting strain was designated ED10, and the situation at the $\mathrm{fts} H$ locus is shown in Fig. 8A.

Analyses of transcription. Isolation of total RNA, Northern analyses, and primer extension were performed as described previously (42). The following synthetic oligonucleotides complementary to the noncoding strands were used as hybridization probes: ON5 (5'-CACGTTCATCGTGTCCC-3'; internal part of $f t s H)$ and ON6 (5'-AGTAGCTCACAACCCCG-3'; 5' end of fts $H$ ). These oligonucleotides were labeled at their $5^{\prime}$ termini with DIG-[11]-ddUTP as described previously (47). To detect $f$ ts $H$ antisense RNA, a DIG-labeled RNA probe was synthesized in vitro with T7 RNA polymerase (Boehringer Mannheim) from the linearized plasmid $\mathrm{pED} \Delta \mathrm{F}$. To construct this plasmid, a 3.6-kb HindIII fragment of chromosomal $B$. subtilis DNA containing most of the fts $H$ gene (27) was first cloned into pACYC177, resulting in pED05. In a second step, the internal 1.1-kb Sst I-HindIII ftsH fragment was recovered from pED05 and cloned into pBluescriptKS ${ }^{+}$. 
A

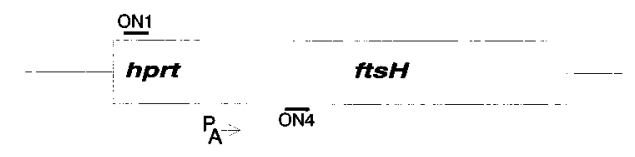

B

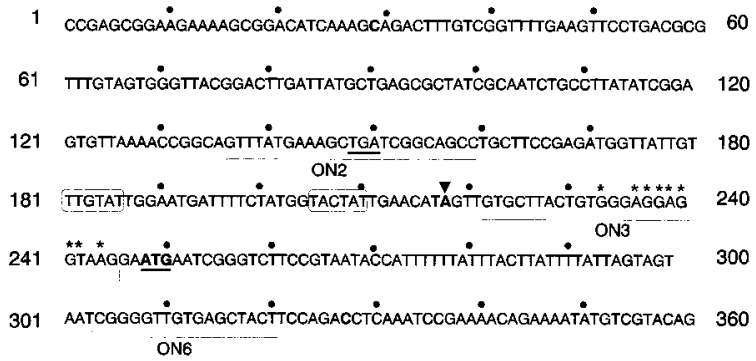

FIG. 2. Nucleotide sequence of the intergenic region between $h p r t$ and fts $H$. (A) Map of the fts $H$ locus. $\mathrm{P}_{\mathrm{A}}$, vegetative promoter; $\mathrm{ON} 1$ and $\mathrm{ON} 4$ denote the locations of the two oligonucleotides which have been used to amplify the upstream and downstream regions of $\mathrm{P}_{\mathrm{A}}$ (see Materials and Methods). (B) DNA sequences of the intergenic hprt-fts $H$ region. Indicated are the putative ShineDalgarno sequence (asterisks above the DNA sequence) and the potential vegetative promoter (the -35 and -10 regions are boxed); the stop codon of hprt and the start codon of $f t s H$ are given in boldface and are underlined. The 5 ' end of mRNA as identified by primer extension is indicated by a boldface letter and by an arrow. The positions of oligonucleotides $\mathrm{ON} 2$ and $\mathrm{ON} 3$, used to replace the promoter, and of ON6, used for primer extension, are indicated.

\section{RESULTS}

Failure of strain UG1 to grow under high salt concentrations overcome by deleting a promoter reading backwards into the $f$ ts $H$ gene. Recently, we published the isolation of the saltsensitive insertion mutant UG1 (10), in which the pBR322 derivative pJH101 (9) has been integrated near the $3^{\prime}$ end of an ORF. Integration was accomplished by first creating a Sau3AI fragment library of chromosomal $B$. subtilis DNA in pJH101 and then transforming the recombinant plasmids into $B$. subtilis 1012. Insertion of the whole plasmid occurred by Campbell-type integration. It turned out that in UG1, the insertion affected an ORF exhibiting significant homology to the fts $H$ genes of $E$. coli (38) and L. lactis (26). Recently, the complete sequence of the $B$. subtilis fts $H$ gene has been published as part of the $B$. subtilis genome sequencing project (27).

First, the insertion site of pJH101 within the fts $H$ gene of UG1 was determined as described under Materials and Methods. It turned out that the $90 \mathrm{C}$-terminal codons of $\mathrm{ftsH}$ have been replaced by 17 foreign plasmid-carried codons (Fig. 1A). Furthermore, we could deduce from the DNA sequences flanking the insertion site that this mutant resulted from the cloning of an internal 875-bp Sau3AI fragment of fts $\mathrm{H}$ into pJH101; as a result of the integration, this 875-bp DNA sequence became duplicated (see Fig. 1A).

In contrast to the wild-type strain, the insertion mutant UG1 did not form colonies under high-salt conditions. To explain this behavior, we envisaged three possibilities: (i) the $\mathrm{FtsH}$ protein modified at its $\mathrm{C}$ terminus is inactive under these conditions; (ii) transcription of the $f t s H$ gene is impaired by the $\mathrm{P}_{\mathrm{Tc}}$ promoter located near the insertion site and reading towards the $5^{\prime}$ end of $f t s H$ (see Fig. 1A; it has been reported that this promoter is active in B. subtilis [19]); and (iii) a combination of both possibilities. To distinguish between these alternatives, we decided to delete the $\mathrm{P}_{\mathrm{Tc}}$ promoter from the chromosome, resulting in strain ED1. Insertion of the plasmid within ED1 took place between codons 514 and 515 of the ftsH

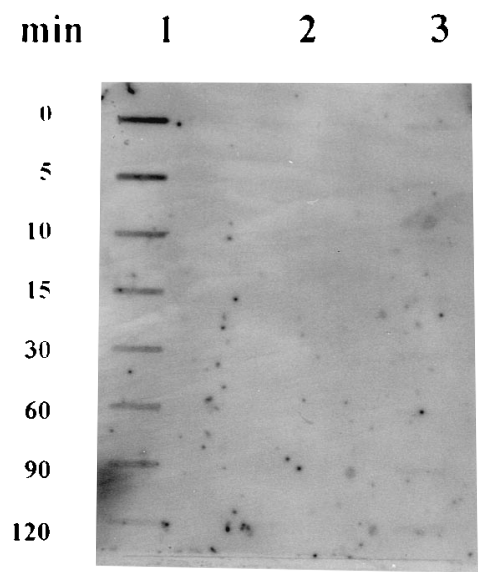

FIG. 3. Detection of antisense RNA. Slot-blots of total RNA of three different strains were done before $(0 \mathrm{~min})$ and $5,10,15,30,60,90$, and $120 \mathrm{~min}$ after osmotic shock. DIG-labeled riboprobe RNA was used as the hybridization probe. RNA $(0.5 \mu \mathrm{g})$ from strains UG1 (lane 1), 1012 (lane 2), and ED1 (lane 3) was tested.

gene. As a result, the last $123 \mathrm{C}$-terminal codons have been replaced by 14 foreign plasmid-derived codons (Fig. 1B).

In contrast to UG1, cells of ED1 could form colonies on $\mathrm{LB}$ plates containing $1.2 \mathrm{M} \mathrm{NaCl}$. This phenotype indicates that the $123 \mathrm{C}$-terminal amino acid residues are dispensable for growth under these conditions. It furthermore suggests that the failure of strain UG1 to grow under high-salt conditions is related to the $\mathrm{P}_{\text {Tc }}$ promoter, which could initiate the production of antisense RNA. Therefore, we attempted to demonstrate antisense RNA.

Insertion mutant UG1 synthesizes antisense RNA complementary to the ftsH mRNA. Total RNA isolated from UG1, ED1, and wild-type B. subtilis was hybridized to DIG-labeled riboprobe RNA complementary to the hypothetical fts $H$ antisense RNA before and at different times after osmotic shock. As can be seen from Fig. 3, a specific signal could be detected, which decreased slowly after the addition of salt (lane 1). This signal could not be detected in either the wild-type strain or the insertion mutant ED1, in which $\mathrm{P}_{\mathrm{Tc}}$ had been deleted (Fig. 3, lanes 2 and 3$)$. We conclude from these results that $\mathrm{P}_{\mathrm{Tc}}$ is active in UG1 and that the RNA originating at this promoter most probably acts as antisense RNA, thereby lowering the amount of $\mathrm{ftsH} R N A$ active in translation. Whereas the production of antisense RNA did not impair growth in the absence of salt, it prevented growth after osmotic upshock, suggesting that the amount of FtsH protein is crucial under these conditions. Although it is rather unlikely, we cannot rigorously exclude the possibility that it is related to the $\mathrm{C}$ terminus of the FtsH protein, which is different in the two insertion mutants.

Physiological analysis of wild-type $B$. subtilis 1012 and insertion mutant UG1 in response to salt stress. In contrast to $B$. subtilis 1012, strain UG1 did not grow in medium containing a high concentration of $\mathrm{NaCl}(10)$. To substantiate this growth defect in more detail and to find out whether it could be rescued by the addition of osmoprotectants, a detailed analysis of the growth characteristics was carried out in SMM.

First, we analyzed the growth of B. subtilis 1012 in the presence of various concentrations of $\mathrm{NaCl}$ with and without three different organic compounds known from $E$. coli to act as compatible solutes. In the absence of an osmoprotectant, growth was slightly diminished at up to $1 \mathrm{M} \mathrm{NaCl}$, a severe reduction occurred at $1.1 \mathrm{M}$, and growth stopped completely at higher concentrations (Fig. 4A). Addition of a compatible sol- 

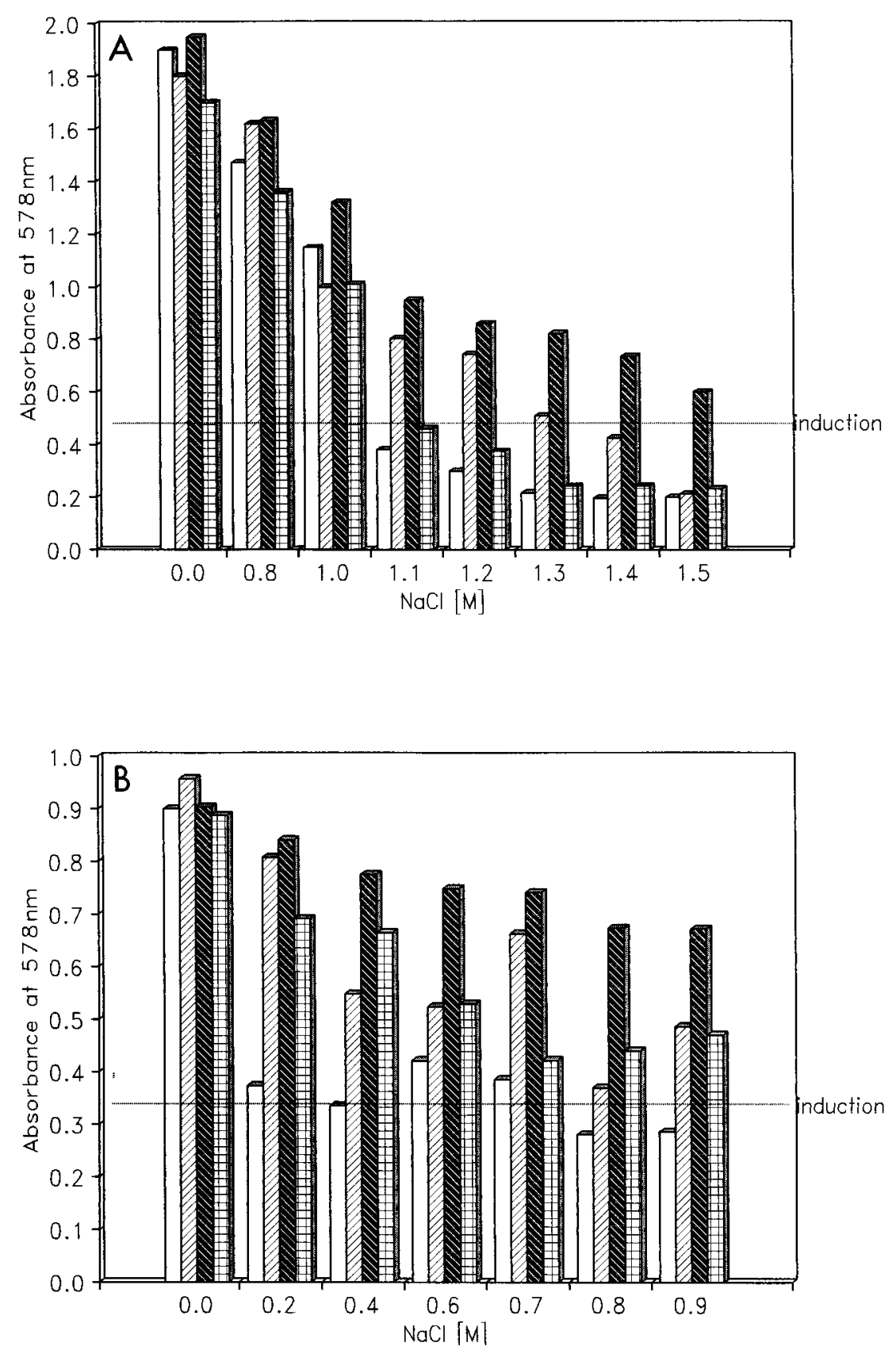

FIG. 4. Growth of two B. subtilis strains in the presence of increasing concentrations of $\mathrm{NaCl}$ and after addition of three different compatible solutes. The cells were grown in SMM to early log phase, and then $\mathrm{NaCl}$ was added (marked by induction) to the final concentration indicated. One culture received no $\mathrm{NaCl}$ treatment. The salt-treated cultures were split into four portions; three received an osmoprotectant to a final concentration of $1 \mathrm{mM}$. The growth of the cultures was monitored by measuring the optical density at $578 \mathrm{~nm}$, and the values after $15 \mathrm{~h}$ of growth are given. (A) Wild-type B. subtilis 1012; (B) B. subtilis UG1. For each set of four bars, growth was measured in the presence of salt alone $(\square)$ and after addition of $1 \mathrm{mM}$ proline (四), glycine betaine ( $\mathbf{N}$ ), or trehalose (辐).

ute affected growth differentially. Whereas trehalose had no influence, both proline and glycine betaine promoted growth. At an $\mathrm{NaCl}$ concentration of $1.5 \mathrm{M}$, glycine betaine still allowed growth, whereas proline had no effect (Fig. 4A).

Next, the insertion mutant UG1 was analyzed. In contrast to its isogenic wild-type strain, growth was already impaired after addition of $0.2 \mathrm{M} \mathrm{NaCl}$ (Fig. 4B). At a concentration of $0.8 \mathrm{M}$ $\mathrm{NaCl}$, growth was completely inhibited. Addition of each of the three compatible solutes promoted growth in the presence of $\mathrm{NaCl}$ up to $0.9 \mathrm{M}$. In comparison to the results with the wild- type strain, glycine betaine turned out to be the most active osmoprotectant, but with UG1, even trehalose promoted growth. Since trehalose was not active in B. subtilis 1012, we interpret its effect on UG1 as being indirect. It is known that trehalose has protective properties on proteins and membranes and as such increases the stress tolerance of a variety of organisms $(3,39)$. The growth of strain ED1 turned out to be comparable to that of B. subtilis 1012 (data not shown).

Transcriptional analysis of the $\mathrm{fts} H$ gene. The results of the physiological analyses suggested that the fts $H$ gene might be 
A
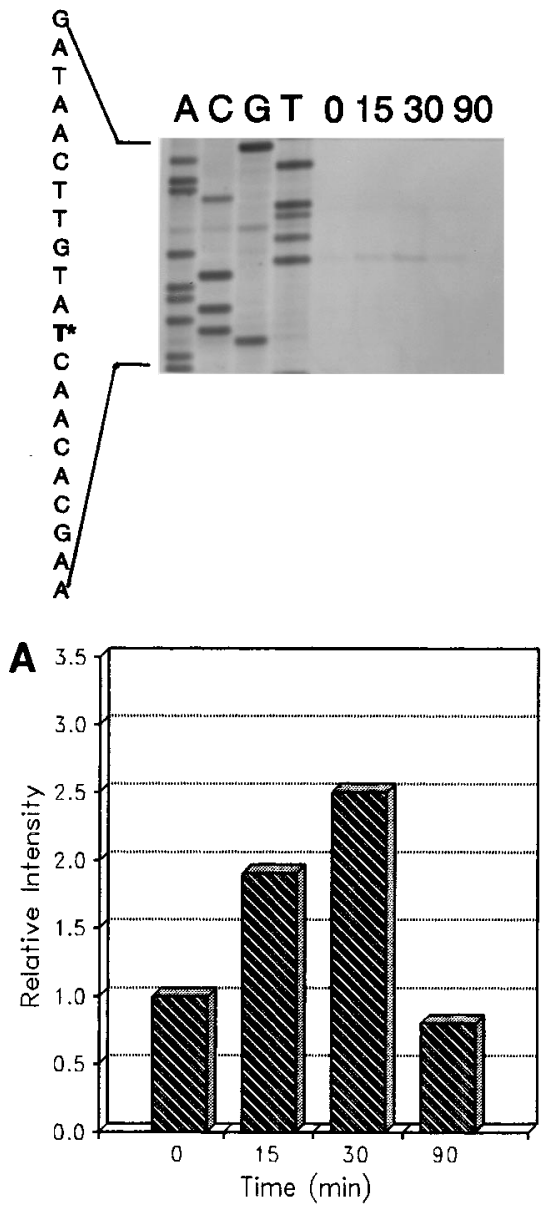

B
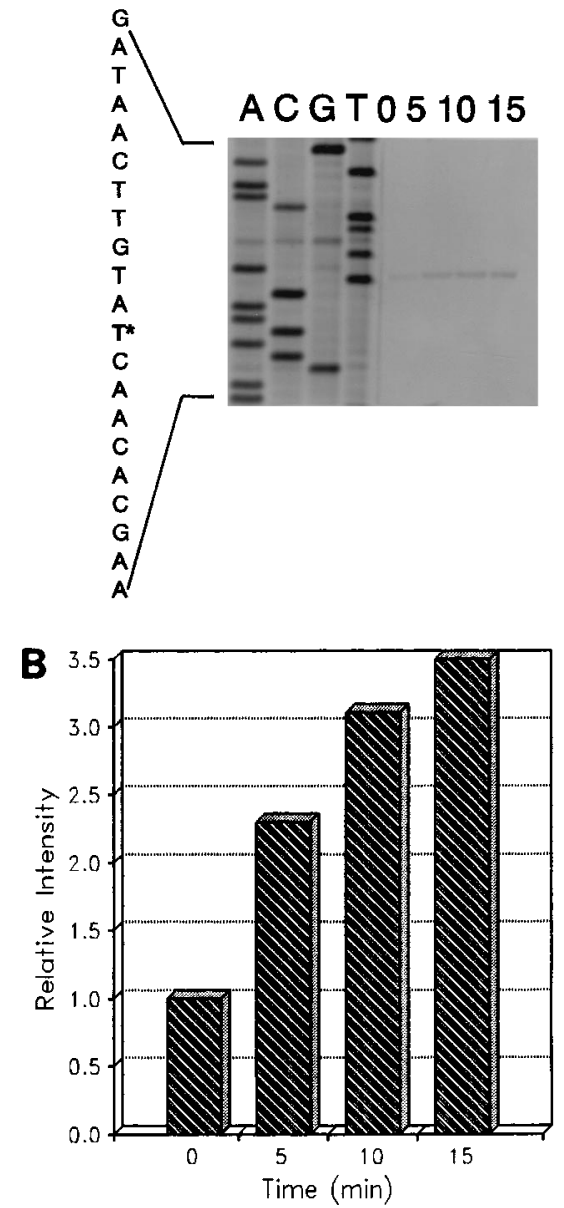

C
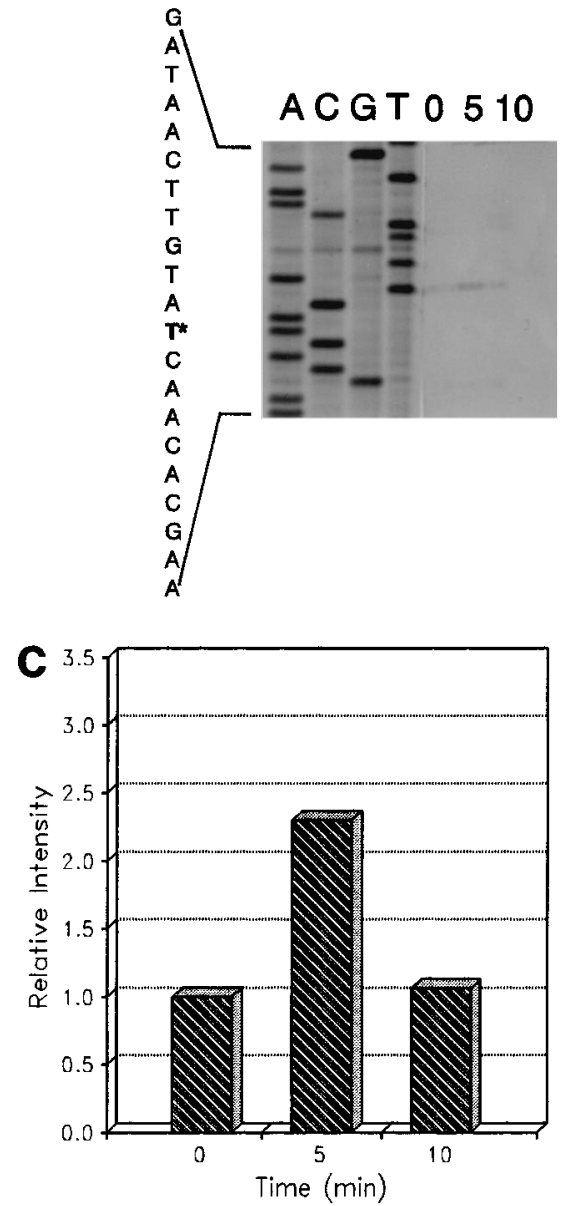

FIG. 5. Mapping of the $5^{\prime}$ end of the $f t s H$ mRNA by primer extension with ON6. Equal amounts of RNA (10 $\left.\mu \mathrm{g}\right)$ were isolated from $B$. subtilis 1012 before ( 0 min) and at the times indicated after osmotic or temperature shock. RNA was from cells treated with $0.8 \mathrm{M} \mathrm{NaCl}(\mathrm{A})$, $10 \%$ glucose (B), and heat (C). The potential startpoints are marked by asterisks. Lanes A, C, G, and T show the dideoxy sequencing ladder obtained with the same primer (ON6) with pED05 as the template. For the graphs corresponding to each panel, the amount of primer extension product was quantified by densitometric scanning.

osmoregulated. First, the amount of mRNA was measured before and after osmotic shock in the wild-type strain by slotblotting and revealed a transient increase in the amount of $f t s H$-specific mRNA (data not shown). This induction was $f t s H$ specific, because the level of $x y n A$ mRNA, which served as an internal control, did not change (data not shown). The $x y n A$ gene encodes $\beta$-xylanase, which is synthesized constitutively during exponential growth (22).

To substantiate this finding and to map the potential transcription start site(s), primer extension experiments were carried out. Total RNA was hybridized with ON6, complementary to the noncoding strand at the beginning of ftsH (see Fig. 2B), and extended with reverse transcriptase. One potential transcription start was mapped, starting with an A at the level of mRNA; this signal changed in intensity after osmotic shock by $\mathrm{NaCl}$ or by glucose (Fig. 5A and B). This start site is within the appropriate distance from a potential $\sigma^{\mathrm{A}}$-dependent promoter (Fig. 2B). As can be seen from the densitometric scanning of the primer extension products, the highest level of $f t s H$-specific mRNA was reached about $30 \mathrm{~min}$ after addition of $0.8 \mathrm{M} \mathrm{NaCl}$ (Fig. 5A) and increased for at least $15 \mathrm{~min}$ after addition of
$10 \%$ glucose (Fig. 5B). It is interesting that no additional start site was activated after osmotic shock.

Since we have observed that growth of strain UG1 was strongly impaired at $52^{\circ} \mathrm{C}$ (it stopped growth immediately after heat induction and did not resume growth for at least $13 \mathrm{~h}$; data not shown), we asked whether fts $H$ also becomes induced after a temperature upshift. The primer extension experiment revealed a transient increase by a factor of about 2.5 and furthermore a potential transcription start site that did not change after heat shock (Fig. 5C). A 2.5-fold induction in the amount of $\mathrm{FtsH}$ protein has also been reported for the fts $H$ gene of $E$. coli (16). These results indicate that a transiently increased expression of the $f t s H$ gene is also essential for the cells to survive heat stress.

To further confirm the transient induction of the $f$ ts $H$ gene by an independent experiment, a transcriptional fusion between $f t s H$ and the promoterless gus gene was constructed and integrated at the amyE locus (Fig. 6A), resulting in strain ED3. Strain ED2 served as a control; it carries the promoterless gus gene integrated at the $a m y E$ locus. Whereas the control strain exhibited no gus activity, the reporter gene in strain ED3 was 
A

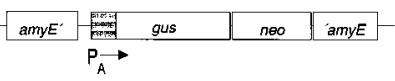

B

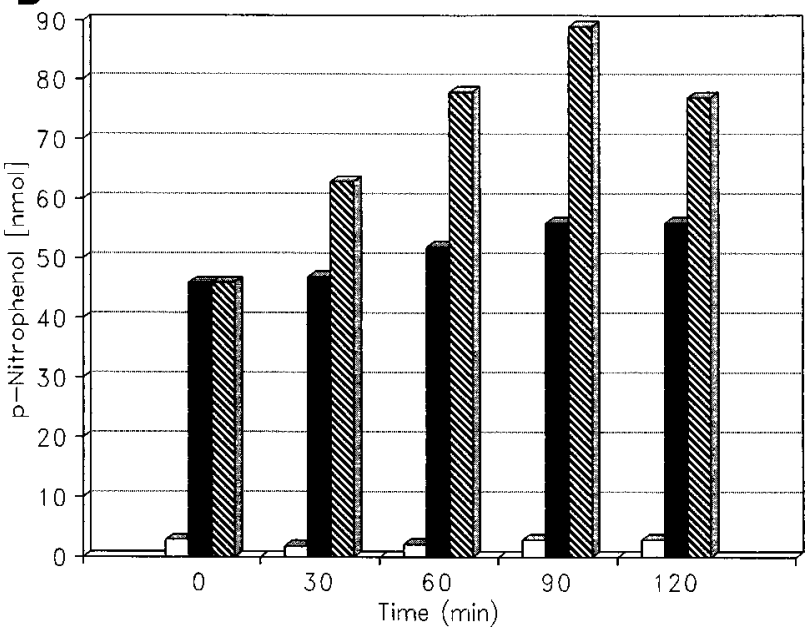

FIG. 6. $\beta$-Glucuronidase activity of a transcriptional $\mathrm{fts} H$-gus fusion. Strains ED2 (control, promoterless gus) and ED3 (fts $H::$ gus fusion) were grown in SMM to mid-log phase (time zero) and then split into two. One half was further incubated in the absence of osmotic stressor, and the other half was challenged with $10 \%$ glucose. Open bars, ED2; solid bars, ED3, no inducer; hatched bars, ED3, $10 \%$ glucose.

expressed, resulting in 40 to $50 \mathrm{nmol}$ of $p$-nitrophenol (Fig. $6 \mathrm{~B})$. After an osmotic upshift with $10 \%$ glucose, the $\beta$-glucuronidase activity increased by a factor of about 2 , resulting in the production of $90 \mathrm{nmol}$ of $p$-nitrophenol. These results are in agreement with the previous findings that the promoter preceding the $f t s H$ gene can be osmotically induced.

From the published sequence of the ftsH gene (27), we deduced a potential $\sigma^{\mathrm{A}}$-dependent promoter preceding $f t s H$ and a putative factor-independent transcription terminator sequence downstream of the gene. Therefore, we suspected that fts $H$ is monocistronic. To prove this hypothesis, Northern blots were performed, which revealed two RNA species with molecular sizes of about 2.1 and $1.5 \mathrm{~kb}$ (Fig. 7). The 2.1-kb species dominated and could correspond by length to the complete $f t s H$ gene. The smaller species could either result from premature termination within $f t s H$, represent a degradation product of the larger species, or be an unspecific signal. Since we detected a signal of about $1.5 \mathrm{~kb}$ in all of our Northern blots dealing with different $B$. subtilis genes, we consider this band nonspecific. It can also be seen from the Northern blot that the larger species increased in its relative amount up to about 5 min after temperature upshift, followed by a decrease, confirming the primer extension results.

Prevention of $f t s H$ induction after osmotic shock leads to growth arrest. If increased amounts of $\mathrm{FtsH}$ protein are really

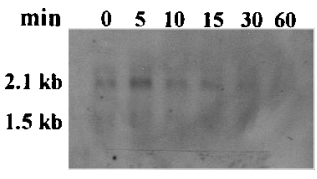

FIG. 7. Northern blot analyses. RNA was isolated from B. subtilis 1012 grown at $37^{\circ} \mathrm{C}$ in $\mathrm{LB}$ and shifted from 37 to $52^{\circ} \mathrm{C}$. The filters were hybridized with DIG-labeled ON5, and $10 \mu \mathrm{g}$ of RNA was applied per lane.
A

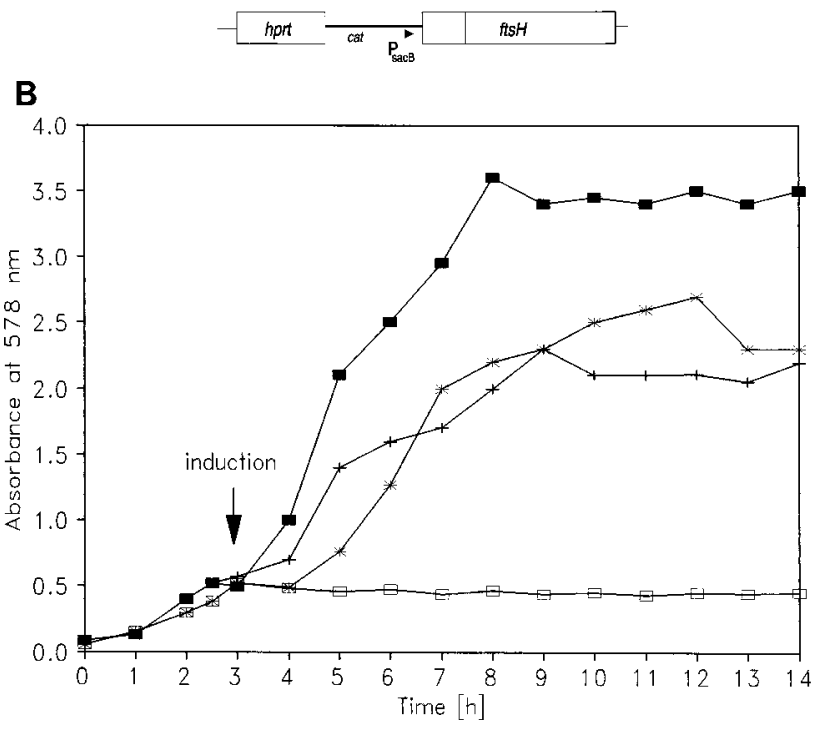

FIG. 8. Growth of wild-type strain 1012 and of strain ED10 in the absence and presence of salt. Both strains were grown in LB to the early exponential phase, and then the culture was split in two. One half was further grown under these conditions, and the other half was challenged with $1.1 \mathrm{M} \mathrm{NaCl} \mathbf{\square}, 1012$, no $\mathrm{NaCl} ; *, 1012, \mathrm{NaCl}$ added; +, ED10, no $\mathrm{NaCl} ; \square, \mathrm{ED} 10, \mathrm{NaCl}$ added. The time of addition of salt is indicated by the arrow.

necessary to allow growth after osmotic shock, prevention of induction of $\mathrm{ftsH}$ should lead to growth arrest. To assess this hypothesis, $\mathrm{P}_{\mathrm{A}}$ was replaced by the sucrose-inducible promoter $\mathrm{P}_{\mathrm{sacB}}$ as described under Materials and Methods, resulting in strain ED10 (Fig. 8A). In preliminary experiments, we found that ED10 could grow in the absence of inducer in LB medium. To test for growth after osmotic shock, strain ED10 was grown to the mid-exponential phase, and the culture was split into two portions. One portion was further incubated without any treatment, and the other was challenged with $1.1 \mathrm{M} \mathrm{NaCl}$. Wildtype strain 1012 served as a control. When strain 1012 was challenged with $1.1 \mathrm{M} \mathrm{NaCl}$, it continued growth at a reduced rate (Fig. 8B). In contrast, strain ED10 arrested growth immediately after addition of salt (Fig. 8B). Growth could be restored by addition of $2 \%$ sucrose (data not shown). These results clearly show that the growth of ED10 after osmotic shock requires increased expression of the fts $H$ gene.

\section{DISCUSSION}

The fts $H$ gene was first described in $E$. coli, where it was identified as a cell division mutation (33). Recently, it could be shown that the original mutant harbors temperature-sensitive mutations in two different genes, one in $\mathrm{ftsH}$ and the other in ftsI, which encodes penicillin-binding protein 3 (4); only the mutation in the latter gene impairs cell division. To avoid further confusion, fts $H$ should be renamed; we suggest imp (for integral membrane protease). The fts $H$ gene was cloned and sequenced and shown to encode an essential integral membrane protein of $70 \mathrm{kDa}$, with an ATPase domain $(37,38)$ homologous to some ATPase subunits of the eukaryotic $26 \mathrm{~S}$ proteasome complex $(28,45)$. A number of $\mathrm{ftsH}$ mutants have been isolated, and there phenotypes have been studied. It turned out that in some mutants, the maturation of penicillinbinding protein 3 and of $\beta$-lactamase was impaired $(4,37)$, 
while in others, the correct insertion of the SecY protein into the inner membrane was affected $(1,2)$. Furthermore, it could be shown that the fts $H$ gene is identical to $h f B$ and that in $f t s H / h f l B$ mutants, degradation of the $\lambda c$ II protein and of the alternative heat shock sigma factor $\sigma^{32}$ was reduced $(15,16$, 36). Quite recently, the FtsH protein was purified and shown to degrade $\sigma^{32}$ in an ATP- and $\mathrm{Zn}^{2+}$-dependent manner (36). Furthermore, we postulate that the FtsH protein might also be responsible for degradation of $\sigma^{\mathrm{s}}$, the stationary-phase sigma factor (24), during vegetative growth. In summary, two functions are thought to be encoded by ftsH: an ATP- and $\mathrm{Zn}^{2+}$ dependent protease and a chaperone-like function involved in the assembly of proteins into and through the cytoplasmic membrane.

The fts $H$ gene of $B$. subtilis was detected during analysis of an insertion mutant which failed to form colonies on LB plates containing $1.2 \mathrm{M} \mathrm{NaCl}$ (10). Here, we show that this failure was due to the synthesis of artificial antisense RNA interfering with the expression of the fts $H$ gene. The inability of UG1 to grow under high salt concentrations could be overcome either by deleting the promoter from which the antisense RNA originated or by extragenic suppressors (data not shown); the nature of the suppressors, which have been mapped at $17^{\circ}$ on the $B$. subtilis chromosome, is completely unclear at present.

A detailed transcriptional analysis of the $f t s H$ gene revealed that this gene is transiently induced at the level of transcription after both osmotic and temperature shock. This has been shown by primer extension and Northern blot analyses and by analysis of a transcriptional ftsH::gus fusion. It has to be mentioned that the gus reporter gene could not be used to monitor promoter activity under salt or heat stress, most probably because of rapid degradation and/or inactivation of the enzyme under these adverse conditions (data not shown).

This behavior identified $f t s H$ as a general stress gene; this group of stress genes is induced by more than one stressor, in contrast to specific stress genes, which respond to only one stress factor (14). It furthermore identified fts $H$ as a member of the class III heat shock genes (34). While regulation of class I genes involves the heat shock element CIRCE, the orf39-encoded protein, and additional unknown factors, those of class II are controlled by the alternate sigma factor $\sigma^{\mathrm{B}}(40)$. Class III heat shock genes are tentatively defined as those whose expression involves neither CIRCE nor $\sigma^{\mathrm{B}}$, and their regulation mechanism is completely unknown to date. Besides $\mathrm{ftsH}$, lon and $\operatorname{clp} C$ are members of this class, all three of which are general stress genes $(20,29)$.

Our results demonstrate that the complete FtsH protein is not essential for survival of the cells under the conditions tested; the 123 C-terminal amino acid residues of the 637 total residues are dispensable. The truncated $\mathrm{FtsH}$ protein which is synthesized in ED1 contains the two potential transmembrane domains and the putative ATP- and $\mathrm{Zn}^{2+}$-binding sites reported for E. coli FtsH $(36,38)$. Using polyclonal antibodies raised against FtsH of $E$. coli, we could show that a protein with a molecular mass of about $70 \mathrm{kDa}$, which we consider the $\mathrm{FtsH}$ protein, is present only in the membrane fraction, from which it could be solubilized by Sarkosyl but not by salt. These experiments carried out with the wild type and UG1 strain yielded identical results (data not shown).

In summary, our data clearly demonstrate that the amount of FtsH protein is crucial for the survival of B. subtilis cells under adverse conditions. After osmotic or temperature shock, the amount of fts $\mathrm{H}$ mRNA is transiently increased two- to threefold, which is most probably followed by a comparable rise in the amount of FtsH protein. Why are increased amounts of FtsH needed after a stress? In E. coli, two substrates of the
FtsH protease have been identified so far, $\sigma^{32}$ and $\lambda$ cII (16, 36); both proteins are transcription factors. Therefore, it is tempting to speculate that in B. subtilis, FtsH is also involved in degradation and/or processing of transcription factors. Clarification of the biological role of FtsH awaits further extensive experimentation, including identification of the target proteins for FtsH by manipulating the amount of $\mathrm{FtsH}$ protein in strain ED10. Then, the protein pattern on two-dimensional gels in the presence of various amounts of $\mathrm{FtsH}$ will be compared with that of the wild-type strain. This should allow the identification of putative target proteins. In addition, experiments are in progress to identify the DNA sequences involved in osmotic and heat regulation.

\section{ACKNOWLEDGMENTS}

We thank U. Geisler for constructing pUG1E, T. Ogura for antibodies, and for communicating unpublished results on the $f t s H$ gene of $E$. coli, and the sequence of the fts $H$ gene of $B$. subtilis. We extend our thanks to D. Nilsson for communicating unpublished data on the $L$. lactis fts $H$ gene and to A. Schulz and U. Zuber for critical reading of the manuscript.

The present work was supported by a grant from the Deutsche Forschungsgemeinschaft to W.S. (Schu 414/11-1).

\section{REFERENCES}

1. Akiyama, Y., T. Ogura, and K. Ito. 1994. Involvement of FtsH in protein assembly into and through the membrane. I. Mutations that reduce retention efficiency of a cytoplasmic reporter. J. Biol. Chem. 269:5218-5224.

2. Akiyama, Y., Y. Shirai, and K. Ito. 1994. Involvement of FtsH in protein assembly into and through the membrane. II. Dominant mutations affecting FtsH functions. J. Biol. Chem. 269:5225-5229.

3. Back, J. F., D. Oakenfull, and M. B. Smith. 1979. Increased thermal stability of proteins in the presence of sugars and polyols. Biochemistry 18:51915196.

4. Begg, K. J., T. Tomoyasu, W. D. Donachie, M. Khattar, H. Niki, K. Yamanaka, S. Hiraga, and T. Ogura. 1992. Escherichia coli mutant Y16 is a double mutant carrying thermosensitive fts $H$ and ftsI mutations. J. Bacteriol. 174:2416-2417.

5. Boch, J., B. Kempf, and E. Bremer. 1994. Osmoregulation in Bacillus subtilis: synthesis of the osmoprotectant glycine betaine from exogenously provided choline. J. Bacteriol. 176:5364-5371.

6. Chang, A. C. Y., and S. N. Cohen. 1978. Construction and characterization of amplifyable multicopy DNA cloning vehicles derived from the P15A cryptic miniplasmid. J. Bacteriol. 134:1141-1156.

7. Csonka, L. N. 1989. Physiological and genetic responses of bacteria to osmotic stress. Microbiol. Rev. 53:121-147.

8. Csonka, L. N., and A. D. Hanson. 1991. Prokaryotic osmoregulation: genetics and physiology. Annu. Rev. Microbiol. 45:569-606.

9. Ferrari, F. A., A. Nguyen, D. Lang, and J. A. Hoch. 1983. Construction and properties of an integrable plasmid for Bacillus subtilis. J. Bacteriol. 154: $1513-1515$.

10. Geisler, U., and W. Schumann. 1993. Isolation of stress mutants of Bacillus subtilis by a novel genetic method. FEMS Microbiol. Lett. 108:251-254.

11. Gottesman, S. 1984. Bacterial regulation: global regulatory networks. Annu. Rev. Genet. 18:415-441.

12. Hanahan, D. 1983. Studies on transformation of Escherichia coli with plasmids. J. Mol. Biol. 166:557-580.

13. Hecker, M., C. Heim, U. Völker, and L. Wölfel. 1988. Induction of stress proteins by sodium chloride treatment in Bacillus subtilis. Arch. Microbiol. 150:564-566.

14. Hecker, M., and U. Völker. 1990. General stress proteins in Bacillus subtilis. FEMS Microbiol. Ecol. 74:197-214.

15. Herman, C., T. Ogura, T. Tomoyasu, S. Hiraga, Y. Akiyama, K. Ito, R Thomas, R. D'Ari, and P. Bouloc. 1993. Cell growth and lambda phage development controlled by the same essential Escherichia coli gene, ftsH/ hflB. Proc. Natl. Acad. Sci. USA 90:10861-10865.

16. Herman, C., D. Thévenet, R. D'Ari, and P. Bouloc. 1995. Degradation of $\sigma^{32}$ the heat shock regulator in Escherichia coli, is governed by HflB. Proc. Natl. Acad. Sci. USA 92:3516-3520.

17. Jefferson, R. A., S. M. Burgess, and D. Hirsh. 1986. $\beta$-Glucuronidase from Escherichia coli as a gene-fusion marker. Proc. Natl. Acad. Sci. USA 83: 8447-8451.

18. Karow, M., and P. Piggot. 1993. The use of gus and lac Z fusions as a double reporter system to study gene expression during $B$. subtilis sporulation, abstract P95. Abstracts of the Seventh International Conference on Bacillus, Paris, France. 
19. Kreft, J., and C. Hughes. 1982. Cloning vectors derived from plasmids and phage of Bacillus. Curr. Top. Microbiol. Immunol. 96:1-17.

20. Krüger, E., U. Völker, and M. Hecker. 1994. Stress induction of $c l p C$ in Bacillus subtilis and its involvement in stress tolerance. J. Bacteriol. 176: 3360-3367.

21. Li, M., and S.-L. Wong. 1992. Cloning and characterization of the groESL operon from Bacillus subtilis. J. Bacteriol. 174:3981-3992.

22. Lindner, C., J. Stülke, and M. Hecker. 1994. Regulation of xylanolytic enzymes in Bacillus subtilis. Microbiology 140:753-757.

23. Lucht, J. M., and E. Bremer. 1994. Adaptation of Escherichia coli to high osmolarity environments: osmoregulation of the high-affinity glycine betaine transport system ProU. FEMS Microbiol. Rev. 14:3-20.

24. McCann, M. P., J. P. Kidwell, and A. Matin. 1991. The putative $\sigma$ factor KatF has a central role in development of starvation-mediated general resistance in Escherichia coli. J. Bacteriol. 173:4188-4194.

25. Measures, J. C. 1975 . Role of amino acids in osmoregulation of non-halophilic bacteria. Nature (London) 257:398-400.

26. Nilsson, D., A. A. Lauridsen, T. Tomoyasu, and T. Ogura. 1994. A Lactococcus lactis gene encodes a membrane protein with putative ATPase activity that is homologous to the essential Escherichia coli fts $H$ gene product. Microbiology 140:2601-2610.

27. Ogasawara, N., S. Nakai, and H. Yoshikawa. 1994. Systematic sequencing of the 180 kilobase region of the Bacillus subtilis chromosome containing the replication origin. DNA Res. 1:1-14.

28. Rechsteiner, M., L. Hoffman, and W. Dubiel. 1993. The multicatalytic and 26 S proteases. J. Biol. Chem. 268:6065-6068.

29. Riethdorf, S., U. Völker, U. Gerth, A. Winkler, S. Engelmann, and M. Hecker. 1994. Cloning, nucleotide sequence, and expression of the Bacillus subtilis lon gene. J. Bacteriol. 176:6518-6527.

30. Saito, H., T. Shibata, and T. Ando. 1979. Mapping of genes determining nonpermissiveness and host-specific restriction to bacteriophages in Bacillus subtilis Marburg. Mol. Gen. Genet. 170:117-122.

31. Sambrook, J., E. F. Fritsch, and T. Maniatis. 1989. Molecular cloning: a laboratory manual, 2nd ed. Cold Spring Harbor Laboratory Press, Cold Spring Harbor, N.Y.

32. Sanger, F., S. Nicklen, and A. R. Coulson. 1977. DNA sequencing with chain-terminating inhibitors. Proc. Natl. Acad. Sci. USA 74:5463-5467.

33. Santos, D., and D. F. Almeida. 1975. Isolation and characterization of a new temperature-sensitive cell division mutant of Escherichia coli K-12. J. Bacteriol. 124:1502-1507.

34. Schulz, A., B. Tzschaschel, and W. Schumann. 1995. Isolation and analysis of mutants of the dnaK operon of Bacillus subtilis. Mol. Microbiol. 15:421-429. 35. Spizizen, J. 1958. Transformation of biochemically deficient strains of $B a$ cillus subtilis by deoxyribonucleate. Proc. Natl. Acad. Sci. USA 44:407-408.

36. Tomoyasu, T., J. Gamer, B. Bukau, M. Kanemori, H. Mori, A. J. Rutman, A. B. Oppenheim, T. Yura, K. Yamanaka, H. Niki, S. Hiraga, and T. Ogura. Escherichia coli FtsH is a membrane-bound, ATP-dependent protease which degrades the heat-shock transcription factor $\sigma^{32}$. EMBO J., in press.

37. Tomoyasu, T., K. Yamanaka, K. Murata, T. Suzaki, P. Bouloc, A. Kato, H. Niki, S. Hiraga, and T. Ogura. 1993. Topology and subcellular localization of FtsH protein in Escherichia coli. J. Bacteriol. 175:1352-1357.

38. Tomoyasu, T., T. Yuki, S. Morimura, H. Mori, K. Yamanaka, H. Niki, S. Hiraga, and T. Ogura. 1993. The Escherichia coli FtsH protein is a prokaryotic member of a protein family of putative ATPases involved in membrane functions, cell cycle control, and gene expression. J. Bacteriol. 175:1344 1351.

39. van Laere, A. 1989. Trehalose, reserve and/or stress metabolite? FEMS Microbiol. Lett. 63:201-210.

40. Völker, U., S. Engelmann, B. Maul, S. Riethdorf, A. Völker, R. Schmid, H. Mach, and M. Hecker. 1994. Analysis of the induction of general stress proteins of Bacillus subtilis. Microbiology 140:741-752.

41. Völker, U., H. Mach, R. Schmid, and M. Hecker. 1992. Stress proteins and cross-protection by heat shock and salt stress in Bacillus subtilis. J. Gen. Microbiol. 138:2125-2135.

42. Wetzstein, M., U. Völker, J. Dedio, S. Löbau, U. Zuber, M. Schiesswohl, C Herget, M. Hecker, and W. Schumann. 1992. Cloning, sequencing, and molecular analysis of the dnaK locus from Bacillus subtilis. J. Bacteriol. 174:3300-3310.

43. Whatmore, A. M., J. A. Chudek, and R. H. Reed. 1990. The effects of osmotic upshock on the intracellular solute pools of Bacillus subtilis. J. Gen. Microbiol. 136:2527-2535.

44. Whatmore, A. M., and R. H. Reed. 1990. Determination of turgor pressure of Bacillus subtilis: a possible role for $\mathrm{K}^{+}$in turgor regulation. J. Gen. Microbiol. 136:705-712.

45. Wolfe, K. H. 1994. Similarity between putative ATP-binding sites in land plant plastid ORF2280 proteins and the FtsH/CDC48 family of ATPases. Curr. Genet. 25:379-383.

46. Yanisch-Perron, C., J. Vieira, and J. Messing. 1985. Improved M13 phage cloning vectors and host strains: nucleotide sequences of the M13mp18 and pUC19 vectors. Gene 33:103-119.

47. Zuber, U., and W. Schumann. 1991. Tn5cos: a useful tool for restriction mapping of large plasmids. Gene 103:69-72. 